\title{
PARAMETER ESTIMATION AND MOTION TRACKING OF PACK ICE FROM FY-3/MERSI IMAGES
}

\author{
Ying Zhou ${ }^{1,}$, Juan $\mathrm{Du}^{1}$, Yi Zhang ${ }^{1}$, Cailan Gong ${ }^{2}$, Yong $\mathrm{Hu}^{2}$ \\ ${ }^{1}$ School of Remote Sensing and Information Engineering, Wuhan University, China - (zhouying8578, dujuan_rs, ivory2008) \\ @ whu.edu.cn \\ ${ }^{2}$ Shanghai Institute of Technical Physics, Chinese Academy of Sciences, China - (gcl, huyong) @ mail.sitp.ac.cn
}

\section{Commission III, WG III/9}

KEY WORDS: Sea Ice, Parameter Estimation, Motion Tracking, FY-3/MERSI, Fram Strait

\begin{abstract}
:
A method to estimate the shape parameters and track the motion velocity of pack ice is presented. The method consists of sea ice recognition, pack ice extraction, parameters estimation and motion tracking. We try to estimate the shape parameters and track the motion velocity from FY-3/MERSI images of Fram strait, which were covered by cloud less than 30\%. It found that the pack ice concentration significantly decreases faster than sea ice concentration. The two parameters indicate the distribution difference between sea ices and pack ices. The change of the perimeter and mean clamp diameter are obvious owing to they were sensitive to the edge of the pack ices. But the small change of roundness, convexity and width-height ratio indicate the shape similarity of pack ices in various size. More than $80 \%$ of the pack ices in the study region are tracked successfully by the proposed method. The resulting motion vectors in the overlapping zones are found to match well with the polar daily grid sea ice motion vectors provided by the National Snow and Ice Data Centre. The method can provide the actual motion vector of pack ices to improve the distribution and details of the grid-to-grid motion vectors.
\end{abstract}

\section{INSTRUCTION}

Arctic sea ice is an important climate driver that interacts with both the atmosphere and oceans from regional to global scales. For example, due to its high reflectance of solar radiation, the variation of sea ice over the Arctic substantially modifies the energy balance of the entire Earth climate system (Stroeve et al., 2012). It is well-known that the Arctic sea ice is in a constant state of deformation and motion. Sea ice deformation and motion are the unique components of the Arctic geophysical environment. Knowledge of the Arctic sea ice deformation and motion is of great importance for modelling the global climate and ship navigation in the Arctic Ocean (Serrezev et al., 2000; Zege et al., 2015).

The Fram Strait (Fig.1) is the main gate for Arctic ice export, with historically about $10 \% \sim 15 \%$ of the total sea ice mass exported each year. And the magnitude of the flux is thus thought to provide a measure of the net ice production in the Arctic Ocean (Kwok et al., 2004; Smedsrud et al., 2011). The ice in the Fram Strait region is located in the marginal ice zone (MIZ), which is defined as the part of the ice pack that is affected by the open ocean. The MIZ there has a width scale of the order of $100 \mathrm{~km}$ and it is characterized by small ice floes, that lead to a higher mobility than in the perennial ice zone (Leppäranta and Hibler, 1987). The Fram Strait region is subject to a strong background flow due to strong winds and the East Greenland current (EGC) causing the southward advection of the ice with drift velocities of up to $1 \mathrm{~m} / \mathrm{s}$, the highest in the whole Arctic (Leppäranta, 2011). Knowledge of the ice drift in this region can be used to improve ice drift models, which are crucial to forecast the spreading of pollutants (Thorndike, 1986).

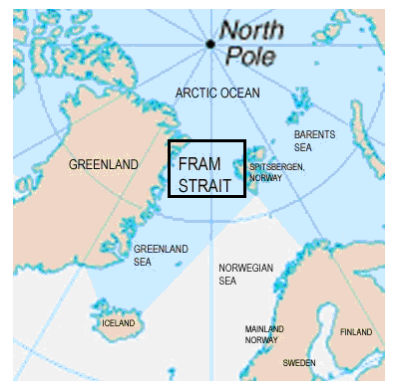

Fig. 1 The study region in the Fram Strait.

During the Arctic summer the Fram Strait is difficult to access for scientists and satellite remote sensing is a primary source of data. Microwave radiometers are preferred to thermal infrared sensors over polar regions often obscured by clouds, because the microwave radiation is less susceptible to atmospheric scattering which does affect shorter infrared wavelengths. To effectively study the complex deformation and motion of Arctic sea ice, more reliable estimates of sea ice motion from satellite data are needed. A large amount of high-quality ocean/ice data has become available for research use. These include data from the Scanning Multichannel Microwave Radiometer (SMMR), the NASA Scatterometer (NSCAT), the Quick Scatterometer (QuikSCAT), the Special Sensor Microwave/Imager (SSM/I), and the Advanced Microwave Scanning Radiometer for the Earth Observing System (AMSR-E) (Zhao et al., 2002; Haarpaintner, 2006; Lavergne et al., 2010). Satellite optical data have been used in the past to estimate the motion velocity of sea ice, despite of the difficulty to deal with data often contaminated by atmospheric disturbance (Emery et al., 1991; Flores and Parmiggiani,1995).

\footnotetext{
* Corresponding author
} 
Several methods have been developed for automatically tracking ice motion from a sequence of satellite images. The methods are mostly based on area correlations or feature matching (Emery et al., 1995). Area correlation and feature matching method are two statistical methods that have been used widely and successfully in operational ice tracking. They are statistical make few assumptions about the dynamics of seaice motion (Buehner et al., 1997). As the most widely used method, the maximum cross-correlation method (MCC) computes the motion vector based on the correlation between the template areas in two images (Emery et al., 1991; Kwok et al., 1998; Martin and Augstein, 2000). The resolution and accuracy of the sea ice motion obtained by this method depends on the choice of the template and search area. The other method, optical flow method, approximately estimates the true motion velocity field by the change of the pixel grayscale in the sequential images (Salvador and Long, 2003; Petrou et al., 2018). This method is sensitive to light conditions. If imaging light condition change, the motion will be monitored even though the sea ice don't move actually. Both methods only get the average velocity of all sea ice grid-to-grid based on the image grayscale feature, rather than the actual motion of each single ice. Therefore, they are unable to analyse the motion characteristics of sea ice with different size and shape.

The aim of this study is to provide information on the shape and motion of the pack ice in the Fram strait from FY-3/MERSI images. We used imagery in the summer derived from the visible and near-infrared bands of the Medium Resolution Spectral Imager (MERSI) onboard the Fengyun-series satellites FY-3A/B/C. The FY-3/MERSI data are obscured by clouds; hence, the pack ice cannot be extracted from the scenes in cloudy periods. However, in this study we tried to extract the pack ice from all the available MERSI swaths, hence we used clear-sky and fog-contaminated scenes. The procedure used to select the informative MERSI images from all the available swaths and to extract the pack ice is here illustrated.

Spatial resolution is a critical factor in satellite observations of small sea ice, and recent sea ice observations by passive microwaves underline the need for sub-daily maps in regions with a very dynamic sea-ice motion (Frost et al., 2018). The spatial resolution of $250 \mathrm{~m}$ or $1000 \mathrm{~m}$ per pixel of the FY/MERSI data is much finer than the several kilometers of the passive microwave data sets (Spreen et al., 2008). The detailed information of a single pack ice such as area, perimeter and motion velocity can be estimated and analysed from FY3/MERSI with the high spatial resolution of $250 \mathrm{~m}$. And the revisit time is shorter too, because one of the three operational MERSI sensors is onboard the same satellite. Due to the larger swath width of MERSI, only one of the three operational MERSI sensors provides more data than microwave data. Using all the swaths available from the three MERSI sensors, the revisit time of the MERSI data set over the Fram Strait is a few hours, but many scenes are obscured by clouds.

In this paper, we propose the method that tries to estimate the shape parameters and track the motion velocity of pack ice from FY-3/MERSI data. In section 2, we introduce our dataset used in the paper and the method for parameters estimation and motion tracking from the FY-3/MERSI images, including the sea ice recognition, pack ice extraction, parameters estimation and motion tracing. A preliminary application to a series FY3/MERSI images is described in section 3, together with the main result analysis and discussion. And in section 4 a brief conclusion is drawn.

\section{DATA AND METHODS}

\subsection{FY-3/MERSI data}

The dataset used in this study was acquired by the Medium Resolution Spectral Imager (MERSI) operational onboard the polar orbiting satellites FY-3A/B/C. The dataset was a series of FY-3/MERSI images covering the Arctic summer (June, July and August). The longitudinal extents of the images were chosen to cover the entire Fram Strait-from $10^{\circ} \mathrm{W}$ to $10^{\circ} \mathrm{E}$. The latitudinal extents were from $77^{\circ} \mathrm{N}$ to $81^{\circ} \mathrm{N}$.

Each FY-3 platform (A, B and C) provides one MERSI scene every 5 min ( 288 per day). There was a total of $\sim 6,000$ scenes over the region of interest for the entire time series. This presents a challenge for both storage and processing of the data. Moreover, the MERSI scenes are obscured by clouds and sea ice recognition is strongly affected by clouds. The sea ice cannot be recognized from scenes where the full extent of the study region covered by clouds. One practical solution is to preselect only the least cloudy MERSI scenes for inclusion into the dataset. At first, the sequence of MERSI scenes was visually inspected to discard non-informative scenes. The discarded scenes were scenes where the sea ice area was fully covered by clouds, scenes where the sea ice area was partially covered by clouds (for more than $30 \%$ of the presumed area) and scenes where the sea ice area was so much contaminated by fog or by other atmospheric disturbance to compromise the recognition of the sea ice. The selected data were scenes where the sea ice area was in a portion of clear sky, was partially obscured by clouds (presumably less than $30 \%$ of the area) or was presumably detectable behind the fog.

As second step, four pre-procedures were implemented to all the selected data, including the radiation correction, map navigation, geometric registration and image cutting. Fig.2 shows two pre-processed MERSI scenes recorded on June 10, 2014 and July 14,2014. The pre-processed images were projected to a polar stereographic projection and cut to 1600 pixels multiply by 1600 pixels (i.e. the area of study region was $160000 \mathrm{~km}^{2}$ owing to the resolution is $250 \mathrm{~m}$ ).

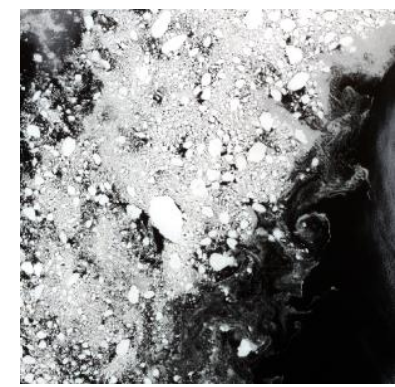

(a)

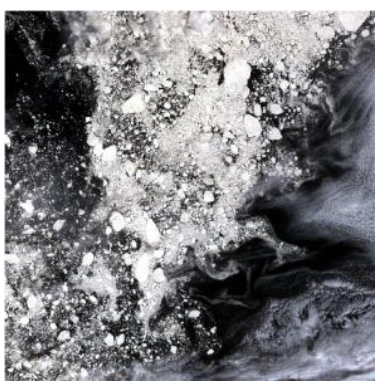

(b)
Fig. 2 The pre-processed MERSI images recorded on (a) June 10, 2014, (b) July 14, 2014.

\subsection{Sea ice recognition}

There were sea ices, sea water and a small amount of cloud in the pre-processed image (see Fig.2 for an example). The sea ice pixels were estimated in each single image by recognizing and removing the cloud pixels and the sea water pixels. And the discriminants for cloud recognition and sea water recognition are established based on the different spectral characteristics of sea ice, cloud and sea water. With the discriminants, cloud 
pixels and sea water pixels were removed and the sea ice pixels were remained in the images.

According to the reflectance spectral characteristics, significant difference among the sea ice, sea water and cloud in the shortwave infrared $(1.55 \sim 1.75 \mu \mathrm{m})$. The cloud pixels were recognized based on the rather higher reflectance than sea ice and sea water. In order to reduce the influence of atmospheric radiation and instrument for improving the reflectance characteristics of cloud, both the Normalized Difference Snow Index (NDSI) (Han et al., 2005) and reflectivity of channel 6 with central wavelength at $1.64 \mu \mathrm{m}$ were used as the criterion for cloud recognition. Therefore, the cloud recognition discriminant was given by

$$
\left\{\begin{array}{c}
N D S I<T_{n d i i} \\
\rho_{6}>T_{b 6}
\end{array}\right.
$$

Where the NDSI was given by

$$
N D S I=\frac{\rho_{2}-\rho_{6}}{\rho_{2}+\rho_{6}}
$$

Where $\rho_{2}$ and $\rho_{6}$ were the reflectivity of channel 2 and channel 6, $T_{n d s i}$ and $T_{b 6}$ were the segmentation thresholds for the NDSI image and channel 6 image. The two thresholds for segmentation were necessarily different scene by scene, due the different cloud conditions present over the study region at the time of the acquisition. In this paper, the thresholds were determined automatically by the OTSU method (Otsu, 1975) for each image. The sea ice and sea water pixels were left by removing the recognized cloud pixels.

In the spectral region from $0.47 \mu \mathrm{m}$ to $0.87 \mu \mathrm{m}$, sea water has significantly lower reflectance than sea ice. Comparing with the sea ice, the reflectance of sea water decreased obviously over the spectral regions where channel 1 and channel 2 of FY-3/ MERSI covered. Then we divided the reflectivity of channel 2 by the reflectivity of channel 1 to get the reflectivity ratio. The reflectivity ratio enhanced the difference between the sea ice and sea water, so that it was available for sea water recognition. Moreover, the reflectance of sea water is much lower than sea ice at $0.6 \mu \mathrm{m}$, so the reflectivity of channel 3 with central wavelength at $0.65 \mu \mathrm{m}$ was included the criterion for sea water recognition. Finally, the sea water recognition discriminant was given by

$$
\left\{\begin{array}{c}
\rho_{1} / \rho_{2}<T_{b 1 / b 2} \\
\rho_{3}>T_{b 3}
\end{array}\right.
$$

Where $\rho_{1}$ and $\rho_{3}$ were the reflectivity of channel 1 and channel 3, $T_{b 1 / b 2}$ and $T_{b 3}$ were the segmentation thresholds for the reflectivity ratio image and channel 3 image. Then only sea ice pixels were left after removing the sea water pixels.

\subsection{Pack ice extraction}

The recognized sea ice was consisting of single pack ices and trash ices around the single pack ices (see Fig.3 for an example). The single pack ices were rather brighter than the trash ices. Comparing with the defined edge and range of the single pack ices, the trash ices were mixing complexly because of the variation of reflectance and grayscale distribution. So, we used this difference between single pack ices and trash ices in grayscale and shape to distinguish the single pack ices from the trash ices. The method combining gradient and segmentation was presented to extract single pack ices.

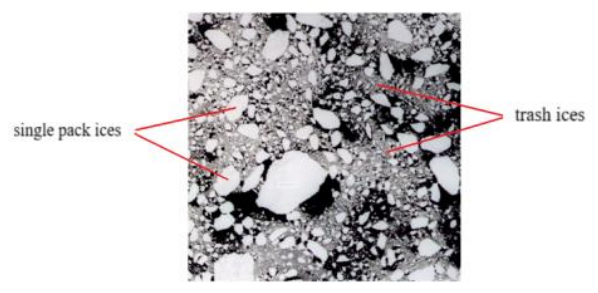

Fig.3 Single pack ices and trash ices in a part of the enlarged result of sea ice recognition.

Firstly, Gradient operators in four directions (Fig. 4) were applied to the result of sea ice recognition and four gradient images were obtained. In the gradient images, trace ices area and the edge of single pack ices presented brighter than the single pack ices due the grayscale variation. The result of sea ice recognition was segmented by using the threshold $T_{i}$ of each gradient image:

$$
g(x, y)=\left\{\begin{array}{c}
0 \\
f(x, y)
\end{array} \quad \operatorname{grad}_{i}(x, y) \geq T_{i}, \quad i=1,2,3,4\right.
$$

Where $f(x, y)$ was the grayscale of one pixel in the result of sea ice recognition, $\operatorname{grad}(x, y)$ was the gradient of the same pixel in one of direction. The determination of $T_{i}$ was crucial in the segmentation, and was obtained by the analysis of the grayscale distribution in the gradient images. In this paper, one third of the standard deviation of all non-zero pixels in each gradient image was defined as the threshold $T_{i}$.

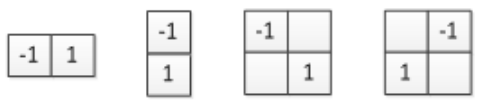

Fig.4 Gradient operators in four

Then the most pixels of the single pack ices were extracted by the gradient segmentation. But some trash ices were not distinguished because of the gradient was not sensitive to these trash ices with small variation of the grayscale. According to the difference of grayscale between the single pack ices and remained trash ices, the binarization image was obtained through adaptive threshold segmentation as

$$
h(x, y)= \begin{cases}1 & g(x, y) \geq T_{\text {block }} \\ 0 & \end{cases}
$$

Where $T_{\text {block }}$ was obtained by the OTSU method based on the grayscale of the gradient segmentation result. So if the gradient of one pixel in the result of sea ice recognition was less than $T_{i}$ and the grayscale of that pixel was more than $T_{\text {block }}$, the pixel was extracted inclusion into single pack ices. Finally, in order to improve the holes and Isolated points in the binarization image, the image was morphological processed by opening-and-closing operation to improve the result of pack ice extraction.

\subsection{Parameters estimation}

After the sea ice recognition, the pixel set of sea ice were obtained and used for the sea ice parameters extraction. Sea ice extent and sea ice concentration which indicated the distribution 
of all sea ices were calculated based on the pixel set. The sea ice extent was estimated from multiplying the number of total sea ice pixels by the area of one pixel $\left(250 \mathrm{~m} \times 250 \mathrm{~m}, 0.0625 \mathrm{~km}^{2}\right)$. The sea ice concentration was estimated from dividing the presumed total area of the pre-processed image $\left(160000 \mathrm{~km}^{2}\right)$ by the sea ice extent estimated previously.

The sea ice concentration indicates the proportion of sea ice in the whole study area. But the composition and distribution of pack ices and trash ices may be different in the regions with same sea ice concentration. In order to comprehensively characterize the distribution of pack ices, pack ice extent and a new parameter named as pack ice concentration was estimated from the pixel set of all pack ices. Based on the pack ice extraction, the pixel set of each single pack ice was obtained. Pack ice extent was calculated by adding all the pixel number of each pack ice together and multiplying by the area of one pixel. And the pack ice concentration was defined as the ratio of pack ice extent $S_{\text {pack }}$ to the total image area $S_{\text {total }}$

$$
B=\frac{S_{\text {pack }}}{S_{\text {total }}} \times 100 \%
$$

Fig. 3 shows the pack ice in different size and shape due to the melting and crushing. The parameters which indicated the shape feature were estimated based on the pixel set of each pack ice. The area of one pack ice was estimated from multiplying the pixel number of the pack ice by the area of one pixel. According to the pixel set of a pack ice, the edge was defined by edge extraction method and the perimeter was estimated from the extracted edge. The pack ices were in various and irregular shape. It was difficult to analyse the shape feature of pack ice by using only one parameter. In this paper, four parameters of extracted pack ice, including mean clamp diameter, roundness, convexity and width-height ratio, were estimated for shape feature analysis.

If two parallel lines rotating between 0 to $180^{\circ}$ were used to clamp the edge of a pack ice, the distance between the two lines was determinate by the edge and shape of the pack ice. So, the mean distance between the two parallel lines in different rotation angles was defined as the mean clamp diameter, which was calculated by:

$$
L=\underset{\theta \in\left[0,180^{\circ}\right]}{\operatorname{mean}}[\max (x \sin \theta+y \cos \theta)-\min (x \sin \theta+y \cos \theta)]
$$

Where $x, y$ were the pixel coordinates of the pack ice, $\theta$ was the rotation angle. The roundness was defined as the ratio of the perimeter of a pack ice to the perimeter of a round which had the same area as this pack ice. It was calculated by:

$$
R=\frac{P^{2}}{4 \pi A}
$$

Where $P$ was the perimeter of a pack ice, $A$ was the area of the pack ice. The roundness indicated the shape complexity and proximity to a round. When a pack ice changed continuously closer to a round, the roundness would reduce. The convexity was defined as the ratio of the perimeter to the mean clamp diameter of a pack ice. It indicated the concavity and convexity of a pack ice. Moment method is effective to analysis the shape feature. According the moment determination, the Major axis length and minor axis length were defined as:

$$
\begin{aligned}
& M_{1}=2\left[\frac{2\left(\mu_{20}+\mu_{02}+\sqrt{\left(\mu_{20}-\mu_{02}\right)^{2}+4 \mu_{11}^{2}}\right)}{\mu_{00}}\right]^{1 / 2} \\
& M_{2}=2\left[\frac{2\left(\mu_{20}+\mu_{02}-\sqrt{\left(\mu_{20}-\mu_{02}\right)^{2}+4 \mu_{11}^{2}}\right)}{\mu_{00}}\right]^{1 / 2}
\end{aligned}
$$

Where $\mu_{20}=\sum(x-\bar{x})^{2}$,

$$
\begin{aligned}
& \mu_{02}=\sum(y-\bar{y})^{2} \\
& \mu_{11}=\sum(x-\bar{x})(y-\bar{y}) \\
& \mu_{00}=\text { the area of the pack ice }=A
\end{aligned}
$$

The width-height ratio was defined the ratio of the major axis length to the minor axis length. The small value of width-height ratio indicates the pack ice is long and narrow.

\subsection{Motion tracking}

The other goal of this paper is to develop a completely objective method for computing the motion velocity of pack ice from sequential images. Comparing the classical ice tracking methods such as MCC method, which computed grid-to-grid ice velocity in Fram Strait (Emery, 1991), the proposed method computed the velocity of each single pack ice. Due to the large amount of pack ice and the pack ice change quickly in the study region, it is difficult to track the pack ice in very small size. The proposed method was availably implemented to pack ices larger than 40 pixels (i.e. the area of the pack ice to track is larger than $\left.2.5 \mathrm{~km}^{2}\right)$. The velocity was computed according to the displacement of each pack ice from the previous image to the latter image.

As the pack ice motion is subject to wind, current and other forces, the motion velocity of the pack ice would be limited to a maximum (Buehner, 1997; Leppäranta, 2011). On the basis of the maximum velocity multiplying by the acquired time interval of the image pair, we computed the maximum distance where the pack ice would move in the image pair. The circle with the maximum distance as its radius was defined as the searching window in the later image. The correspondence pack ice would be determined in this searching window.

The core concept of the motion tracking method is the matching of the correspondence pack ice (i.e. the same pack ice in the image pair). The pack ice was constantly and gradually changing in the recorded time interval of image pair. The area and shape of the correspondence pack ice changed in a small way. Based on the area and shape of the pack ice, the matching method of correspondence pack ice was developed in two steps. At first, the candidate set of each pack ice in the previous image were determined by comparing the area. If the area difference between a pack ice named as $\mathrm{A}$ in the previous image and a pack ice named as $\mathrm{B}$ in the searching window was less than a given threshold, the pack ice $\mathrm{B}$ was included into the candidate set of pack ice A. As second step, the pack ice A was matched to the correspondence pack ice in the candidate set. The Euclid closeness of shape feature was used as the criterion. The Euclid closeness of shape feature between pack ice A and candidate pack ice was computed by: 


$$
N(A, C)=1-\frac{1}{\sqrt{n}}\left\{\sum_{i=1}^{n}\left[\frac{A\left(u_{i}\right)-C\left(u_{i}\right)}{\max \left(A\left(u_{i}\right), C\left(u_{i}\right)\right)}\right]^{2}\right\}^{1 / 2}
$$

Where $\mathrm{C}$ was one pack ice of the candidate set, $u_{i}$ was the one of the shape parameters. The pack ice with the largest closeness was determined as the correspondence pack ice to pack ice A. The motion velocity of the matched pack ice was computed from the displacement of the barycentric coordinates in the image pair.

\section{RESULTS AND DISCUSSION}

\subsection{Parameters estimation and analysis}

As a demonstration, Table 1 shows the distribution parameters estimated respectively from FY-3/MERSI images recorded on June 10, July 14 and August 18, 2014. Table 2 shows the minimum, maximum, mean and standard deviation of the shape parameters estimated from the three images. It can be seen in the Table 1, the cloud extent in the second image is rather larger. Considering the source FY-3/MERSI image recorded on July 14 the cloud mainly covered in the seawater region. It affects the estimation of seawater extent but has little influence on the estimation of sea ice parameters. In the Table 2, the minimum of the shape parameters is limited to the resolution of FY3/MERSI image owing to the minimum pack ices extracted are same in each image.

\begin{tabular}{|l|l|l|l|}
\hline & Image 1 & Image 2 & Image 3 \\
\hline Sea ice extent $\left(\mathrm{km}^{2}\right)$ & 86945.9 & 57500.8 & 42017.6 \\
Seawater extent $\left(\mathrm{km}^{2}\right)$ & 63467.4 & 50833.1 & 112911.7 \\
Cloud extent $\left(\mathrm{km}^{2}\right)$ & 9586.7 & 51666.1 & 5070.7 \\
Sea ice concentration & $54.3 \%$ & $35.9 \%$ & $26.3 \%$ \\
The number of pack ice & 2983 & 1793 & 854 \\
Pack ice concentration & $15.8 \%$ & $5.1 \%$ & $2.2 \%$ \\
\hline
\end{tabular}

Table 1 The distribution parameters estimated from the three images recorded on June 10, July 14 and August 18, 2014.

It found that the distribution parameters and shape parameters decreased with the fragmentation and melting of sea ice as well as the increased radiation in Arctic summer (Perovich et al., 2009). By comparison, the pack ice concentration significantly decreased faster than sea ice concentration, especially in the second image. It shows that both of the parameters indicate the distribution difference between sea ices and single pack ices.
The change of sea ice concentration indicates the melting and disappearance of whole ice region, while the pack ice concentration indicates the fragmentation and deformation of the pack ice. The pack ices have unique and significant effect on the hydrothermal exchange between ice and water (Steele et al., 1989). The combination of sea ice concentration and pack ice concentration can comprehensively and accurately describe the distribution of sea ice.

Moreover, the change of the perimeter and mean clamp diameter were obvious owing to they were sensitive to the edge of the pack ices, so they can indicate the shape change of pack ice. One reason is that the melting in the summer affects the entire sea ice structure; particularly, it changes the upper layer of ice such as the edge of the pack ice (Perovich et al., 2009). The small difference of roundness, convexity and width-height ratio explained the shape similarity of pack ices in various size. All pack ices were approximately round and convex. However, the maximum of roundness and convexity increased quickly because of the increasing tortuosity and complexity. The area of the pack ice indicates the characteristics and change of ice size. Because the pack ices with different area have different influence on the ship navigation, so statistical analysis of pack ices according to area will be of great help to the safe navigation in Arctic passage (Zhao and Ren, 2000).

\subsection{Motion tracking and validation}

Figs. 5(a)-(c) show the pack ice motion vectors derived from three image pairs (as more fully detailed of the image pairs in Table 3) and the polar daily grid sea ice motion vectors provided by the National Snow and Ice Data Centre (NSIDC). In Figs. 5, black arrows indicate the pack ice motion vectors derived from FY-3/MERSI images. The starting point of the arrow is the mass centre of the tracked pack ice, with longer arrows representing quicker motion velocity. Red arrows indicate the polar daily grid sea ice motion vectors provided by NSIDC in the same scale. More than $80 \%$ of pack ices were tracked in the three image pairs, while some pack ices are not tracked yet, especially in the third image pair. Two reasons are found from the source FY-3/MERSI image as well as the motion tracking method. One reason is that cloud impact on the pack ice extraction and the matching of the correspondence pack ice; hence the pack ice covered by cloud cannot be tracked. Another reason is that the fragmentation and melting of the pack ice affecting the shape parameters estimation and resulting in the error matching of correspondence pack ice.

\begin{tabular}{|c|c|c|c|c|c|c|c|}
\hline \multicolumn{2}{|c|}{} & $\begin{array}{c}\text { Area } \\
\left(\mathrm{km}^{2}\right)\end{array}$ & $\begin{array}{c}\text { Perimeter } \\
(\mathrm{km})\end{array}$ & $\begin{array}{c}\text { Mean clamp } \\
\text { diameter }(\mathrm{km})\end{array}$ & Roundness & $\begin{array}{c}\text { Convexity } \\
\text { Image 1 }\end{array}$ & $\begin{array}{c}\text { Width-height } \\
\text { ratio }\end{array}$ \\
\hline & Minimum & 0.38 & 1.50 & 0.48 & 0.48 & 2.69 & 0.20 \\
& Mean & 1357.06 & 289.00 & 52.10 & 5.40 & 5.55 & 1.00 \\
Image 2 & 8.46 & 7.54 & 2.40 & 0.88 & 3.06 & 0.72 \\
& Standard deviation & 34.40 & 10.09 & 2.69 & 0.37 & 0.18 & 0.18 \\
\hline & Minimum & 0.38 & 1.50 & 0.48 & 0.48 & 2.76 & 0.21 \\
& Maximum & 416.81 & 432.00 & 33.33 & 35.63 & 12.96 & 1.00 \\
Image 3 & Mean & 4.65 & 6.96 & 1.88 & 1.05 & 3.22 & 0.73 \\
& Standard deviation & 17.54 & 15.28 & 2.15 & 1.21 & 0.50 & 0.20 \\
& Minimum & 0.38 & 1.50 & 0.48 & 0.48 & 2.75 & 0.26 \\
& Maximum & 145.25 & 126.00 & 20.09 & 8.70 & 6.92 & 1.00 \\
& Mean & 4.13 & 6.39 & 1.86 & 0.97 & 3.16 & 0.72 \\
\hline
\end{tabular}

Table 2 The distribution parameters estimated from the three images recorded on June 10, July 14 and August 18, 2014. The minimum, maximum, mean and standard deviation of shape parameters were estimated respectively. 


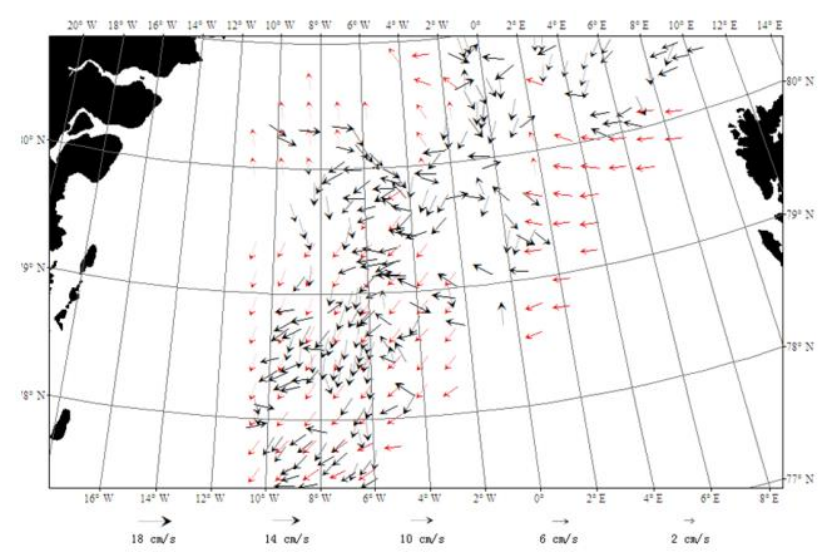

(a)

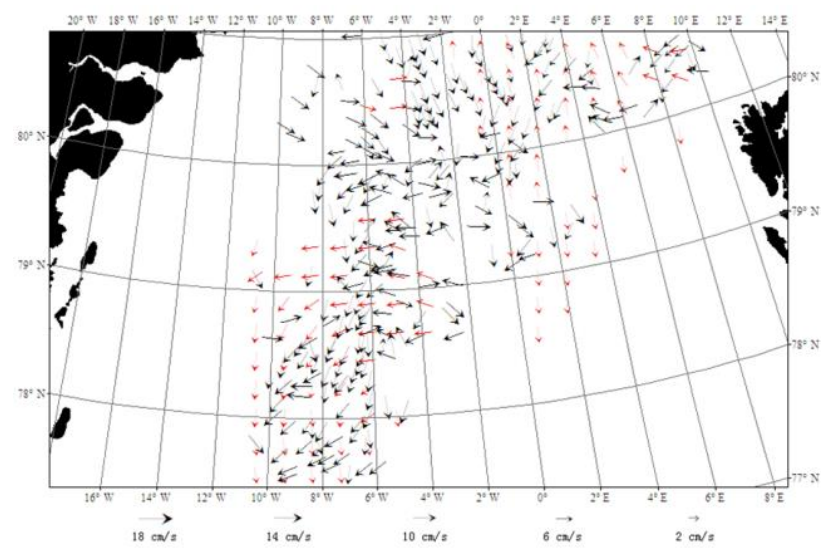

(b)

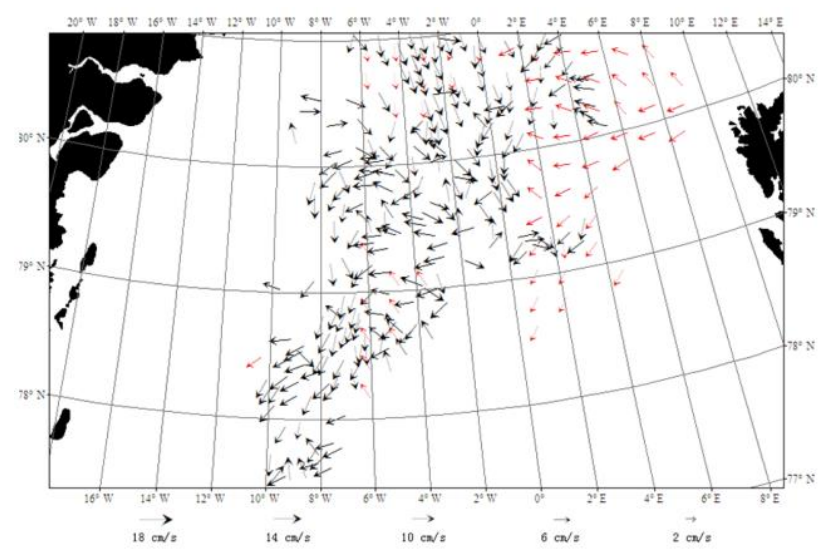

(c)

Fig.5 The pack ice motion vectors tracked from (a) the first image pair, (b) the second image pair and (c) the third image pair (as more fully detailed in Table 3 ). The black arrow shows the pack ice motion vector traced by FY-3/MERSI and the red arrow shows sea ice motion vector provided by NSIDC.The longer arrows represent quicker motion velocity.

\begin{tabular}{|c|c|c|}
\hline Image pair & $\begin{array}{c}\text { Previous image } \\
\text { (record time) }\end{array}$ & $\begin{array}{c}\text { Latter image } \\
\text { (record time) }\end{array}$ \\
\hline 1 & $17: 55$, June 12 & $17: 35$, June 13 \\
2 & $14: 15$, June 13 & $13: 55$, June 14 \\
3 & $12: 15$, June 14 & $11: 55$, June 15 \\
\hline
\end{tabular}

Table 3 Three FY-3/MERSI image pairs for pack ice Motion tracking.
Note that in Figs. 5(a)-(c) the motion vectors map derived from FY-3/MERSI image pairs agree well with the polar daily grid sea ice motion vectors, and they are complementary to each other in the overlap region. The polar daily grid sea ice motion vector is an integrated product from a variety of data such as buoys, AVHRR, SSMR, SSM/I and wind field (Fowler et al., 2013). The mean velocity from the multi-source data is affected by data source quality and fusion algorithms. The motion vector from satellite data was obtained by the maximum crosscorrelation method (MCC). This method assumes a linear displacement of common features between images. It has been shown that the correlation peak broadens and eventually becomes statistically insignificant as rotation of the pack ice increases. Therefore, the product is particularly limiting due to the Fram Strait region locating in the MIZ, where piecewise rotation and translation of the pack ice are often observed. (Vesecky et al. 1988; Kwok et al. 1990). The resulting motion vectors supply the actual motion velocity of each pack ice to improve the distribution and details of sea ice motion vectors in a grid size of $25 \mathrm{~km} \times 25 \mathrm{~km}$. The general circulation pattern can be clearly observed in these maps. Most of the pack ices in the Fram strait were found to flow from north to southwest, matching with the dominant wind caused by the abnormal level pressure field between the Beaufort Sea and the Barents Sea and the ocean currents, Transpolar Drift Stream (Kwok and Pang, 2004; Leppäranta, 2011; Gabrielski et al., 2015). Meanwhile the pack ice motion showed regional difference and oscillatory variation. Due to the turbulence in the atmosphere and ocean, some pack ice even flowed to north or motion as a cyclonic (Colony and Thorndike, 1985; Tsukernik et al., 2010).

\section{CONCLUSIONS}

In this paper we presented a method for the parameters estimation and motion tracking by using the FY-3/MERSI satellite images. Firstly, on the basis of the different spectral characteristic of sea ice, cloud and sea water, the sea ice recognition of FY-3/MERSI image was developed. After the sea ice recognition, the influence of thin cloud and fog were reduced. Secondly, according to the grayscale distribution feature of single pack ice and trash ice, single pack ices were extracted by combining the gradient and segmentation. Thirdly, two distribution parameters, sea ice extent and sea ice concentration, were estimated based on the sea ice recognition. Six shape parameters, including area, perimeter, roundness, mean clamp diameter, convexity and width-height ratio, were estimated according to the range and edge of each pack ice. In order to comprehensively characterize the distribution of pack ices, all pack ices were counted and a new parameter named as pack ice concentration was estimated. Finally, corresponding pack ices were searched and matched in the previous and latter images by using the Euclid closeness of the shape parameters. Then the motion velocity was estimated according to the displacement of corresponding pack ice.

The motion vectors and shape parameters of pack ice in the Fram Strait are analysed using the FY/MERSI images during the summer months. It found that the distribution and shape parameters decreased continuously in the summer. The new parameter, pack ice concentration provided significantly the fragmentation information of the pack ice as an indicator. The pack ices in different size remain similar in roundness, convexity and width-height ratio despite their constant change. Moreover, more than $80 \%$ of the pack ices were tracked and the resulting motion vectors were found to match well with the polar daily grid sea ice motion vectors provided by the NSIDC, 
thus verifying the validity of the proposed method of tracking pack ice motion.

By the proposed method, more detailed shape information of pack ice was extracted to optimize the characteristics indicator of Arctic sea ice. And the prime effect of pack ice motion is superior to the grid-to-grid motion vectors that represent the average velocity of all sea ice in the grid region. Therefore, the proposed method is capable of providing the comprehensive and detailed information of shape and motion for the analysis of Arctic sea ice change and the security of the Arctic Passage development.

\section{ACKNOWLEDGEMENTS}

This work was Supported by National Natural Science Foundation of China (41401490) and the Fundamental Research Funds for the Central Universities (2042019kf0047). The FY3/MERSI data for this work were obtained from the National Satellite Meteorological Centre. The polar daily grid sea ice motion vectors from the web site of the National Snow and Ice Data Centre.

\section{REFERENCES}

Buehner, M., Thompson, K.R., Peterson, I., 1997. An inverse method for tracking ice motion in the marginal ice zone using sequential satellite images. Journal of Atmospheric \& Oceanic Technology, 14(6), 1455-1466.

Colony, R., \& Thorndike, A.S., 1985. Sea ice motion as a drunkard's walk. Journal of Geophysical Research Oceans, 90(C1), doi: 10.1029/JC090iC01p00965.

Emery, W.J., Fowler, C.W., Hawkins, J., et al, 1991. Fram Strait satellite image - derived ice motions. Journal of Geophysical Research: Oceans, 96(C3), 4751-4768.

Emery, W., and Maslanik, J., 1995. Satellite remote sensing of ice motion. Oceanographic Applications of Remote Sensing, M. Ikeda and F. Dobson, Eds., CRC Press, 367-379.

Flores M. M., Parmiggiani F., 1995. Sea-ice velocity fields estimation on Ross Sea with NOAA-AVHRR. IEEE Transactions on Geoscience \& Remote Sensing, 33(5):0-1289.

Fowler, C., Maslanik J., Emery W., \& Tschudi M., 2013. Polar Pathfinder Daily $25 \mathrm{~km}$ EASE-Grid Sea Ice Motion Vectors. Version 2. Boulder, Colorado, USA, NASA National Snow and Ice Data Center Distributed Active Archive Center. http://dx.doi.org/10.5067/LHAKY495NL2T.

Frost, A., Wiehle, S., Singha, S., \& Krause, D., 2018. Sea Ice Motion Tracking from Near Real Time Sar Data Acquired During Antarctic Circumnavigation Expedition. Igarss. doi: 10.1109/IGARSS.2018.8518249.

Gabrielski, A., Badin, G., \& Kaleschke, L., 2015. Anomalous dispersion of sea ice in the fram strait region. Journal of Geophysical Research: Oceans, 120(3), 1809-1824.

Haarpaintner, J., 2006. Arctic-wide operational sea ice drift from enhanced-resolution Quikscat/SeaWinds scatterometry and its validation. IEEE Transactions on Geoscience \& Remote Sensing, 44(1), 102-107.
Han, S.Q., Li, Z.F., Sun, Z.G., 2005. Observational study of MODIS data on sea ice of China's Bohai Sea. Scientia Meteorologica Sinica, 25(6), 624-628.

Kang, D., Im, J., Lee, M. I., \& Quackenbush, L.J., 2014. The MODIS ice surface temperature product as an indicator of sea ice minimum over the arctic ocean. Remote Sensing of Environment, 152, 99-108.

Kwok, R., Cunningham, G.F., Pang, S.S., 2004. Fram strait sea ice outflow. Journal of Geophysical Research, 109(C1), C01009.

Kwok R., Curlander J.C., 1990. An ice-motion tracking system at the Alaska SAR facility. IEEE Journal of Oceanic Engineering, 15(1): 44-54.

Kwok, R., Schweiger A., Rothrock D.A., Pang S., and Kottmeier C., 1998. Seaice motion from satellite passive microwave imagery assessed with ERS SAR and buoy motions, Journal of Geophysical Research, 103, 8191-8214.

Lavergne, T., Eastwood, S., Teffah, Z., Schyberg, H., \& Breivik, L. A., 2010. Sea ice motion from low-resolution satellite sensors: An alternative method and its validation in the Arctic. Journal of Geophysical Research: Oceans, 115(C10), doi: 10.1029/2009JC005958.

Leppäranta, M., and Hibler, W.D., 1987. Mesoscale sea ice deformation in the East Greenland marginal ice zone. Journal of Geophysical Research Oceans, 92(C7), 7060-7070.

Leppäranta, M., 2011. The drift of sea ice. Springer, Netherlands.

Martin, T., and Augstein E., 2000. Large- scale drift of Arctic sea ice retrieved from passive microwave satellite data. Journal of Geophysical Research, 105, 8775- 8788.

Otsu, N., 1975. A threshold selection method from gray-level histograms. Automatica, 11(285-296), 23-27.

Perovich, D.K., Grenfell, T.C., Light, B., Elder, B.C., Harbeck, J., Polashenski, C., et al., 2009. Transpolar observations of the morphological properties of Arctic sea ice. Journal of Geophysical Research Ocean, 114(C1), https://doi.org/10.1029 /2008JC004892.

Petrou, Z.I., Xian, Y., \& Tian, Y.L., 2018. Towards breaking the spatial resolution barriers: an optical flow and superresolution approach for sea ice motion estimation. Isprs Journal of Photogrammetry \& Remote Sensing, 138, 164-175.

Salvador Gutiérrez, Long D. G., 2003. Application of Optical Flow and Scale Space Methods to Sea-Ice Motion in Antarctica. Proceedings of SPIE - The International Society for Optical Engineering, 5155.

Serreze, M.C., Walsh, J.E., Chapin, F.S., Osterkamp, T., Dyurgerov, M., \& Romanovsky, V., et al., 2000. Observational evidence of recent change in the northern high-latitude environment. Climatic Change, 46(1-2), 159-207.

Smedsrud, L.H., Sirevaag, A., Kloster, K., Sorteberg, A., and Sandven, S., 2011. Recent wind driven high sea ice area export in the Fram Strait contributes to Arctic sea ice decline. Cryosphere, 5(4), 821-829. 
Spreen, G., Kaleschke, L., \& Heygster, G., 2008. Sea ice remote sensing using AMSR-E 89-GHz channels. Journal of Geophysical Research, 113(C2), doi:10.1029/2005JC003384.

Steele, M., Morison, J. H., \& Untersteiner, N., 1989. The partition of air-ice-ocean momentum exchange as a function of ice concentration, floe size, and draft. Journal of Geophysical Research, 94(C9), 12739.

Stroeve, J.C., Serreze, M.C., Holland, M.M., Kay, J.E., Maslanik, J., \& Barrett, A.P., 2012. The Arctic's rapidly shrinking sea ice cover: A research synthesis. Climatic Change, 110, 1005-1027.

Thorndike, A.S., 1986. Diffusion of sea ice. Journal of Geophysical Research, 91(C6), 7691-7696.

Tsukernik M., Deser C., Alexander M., et al., 2010. Atmospheric forcing of Fram Strait sea ice export: a closer look. Climate dynamics, 35(7-8): 1349-1360.

Vesecky, J.F., Samadani, R., Smith, M. P., Daida, J. M., \& Bracewell, R.N., 1988. Observation of sea-ice dynamics using synthetic aperture radar images: automated analysis. IEEE Transactions on Geoscience and Remote Sensing, 26(1), 0-48.

Zege, E., Malinka, A., Katsev, I., Prikhach, A., Heygster, G., \& Istomina, L., et al., 2015. Algorithm to retrieve the melt pond fraction and the spectral albedo of arctic summer ice from satellite optical data. Remote Sensing of Environment, 163, 153164.

Zhao, J.P., Ren J.P., 2000. Study on the method to analyze parameters of Arctic sea ice from airborne digital imagery. Journal of Remote Sensing, 4(4), 271-278.

Zhao Y., Liu A.K., Long D.G., 2002. Validation of sea ice motion from QuikSCAT with those from SSM/I and Buoy[J]. IEEE Transactions on Geoscience \& Remote Sensing, 40(6):1241-1246. 